\title{
COLORADOSCHOOLOFMINES
}

EARTH•ENERGY•ENVIRONMENT

Division of ECONOMICS AND Business
WORKING PAPER SERIES

\section{Assessing the Benefits of Air-Quality Improvements in General Equilibrium: A Review}

Jared C. Carbone

Yuzhou Shen

\author{
Working Paper 2019-05 \\ http://econbus-papers.mines.edu/working-papers/wp201905.pdf \\ Colorado School of Mines \\ Division of Economics and Business \\ 1500 Illinois Street \\ Golden, CO 80401
}

July 2019 
Colorado School of Mines

Division of Economics and Business

Working Paper No. 2019-05

July 2019

Title:

Assessing the Benefits of Air-Quality Improvements in General Equilibrium: A Review*

Author(s):

Jared C.Carbone

Division of Economics and Business

Colorado School of Mines

Golden, CO 80401

jcarbone@mines.edu

Yuzhou Shen

Division of Economics and Business

Colorado School of Mines

shen@mines.edu

\section{ABSTRACT}

The vast majority of existing attempts to measure the benefits and costs of air-quality regulations model assume no interaction between the behavioral responses that determine the market-based costs of these policies and the targeted environmental benefits themselves. Nevertheless, general equilibrium theory suggests a number of channels through which important interdependencies might arise, including health impacts on labor supply and the demand for medical care, complementarities between air quality and demand for leisure activities, and interactions between multiple services derived from a common, impacted ecosystem. We develop a unified theoretical framework to assess the nascent literature focused on incorporating air-quality impacts into general equilibrium models. Our primary focus on quantitative studies employing computable general equilibrium (CGE) models. We conclude by identifying priorities for future research in this field.

\section{$J E L$ classifications: D58, Q51, Q52.}

Keywords: air quality, non-market values, computable general equilibrium.

${ }^{*}$ The genesis of the paper stems from Carbone's service on the U.S. Environmental Protection Agency Science Advisory Board subcomittee on economy-wide modeling, so thanks are due to the US EPA staff and the other subcommittee members. All errors are our own. 


\section{Introduction}

Fifty years ago, Ayres and Kneese (1969) established the rationale for an economy-wide approach to modeling the benefits of environmental quality. These pioneers saw natural systems as a source of assimilative capacity for the waste byproducts that underlie human activity. When humans populations are small relative to this capacity, it can safely be left out or treated in a piecemeal fashion with respect to the analysis of environmental quality issues. When humans begin to push the edge of the natural system's capacity, however, the analyst must consider the coupling between the human and natural systems; how human behavior determine environmental outcomes as well as how the environment feeds back to influence humans.

The field of environmental economics has tended to treat benefits of environmental quality (or the costs of environmental degradation) in such a piecemeal fashion. It relies almost exclusively on the logic of the microeconomic theory of consumer behavior to model the impacts of changes in environmental quality. That is, it approaches the measurement of environmental benefits as an exercise in comparative statics in which households maximize utility subject to a given vector of market prices and indices of environmental quality. The welfare change is conceived of as the income change required to compensate the household for an exogenous change in environmental quality, ceteris paribus. Viewing the problem in this way rules out, for example, the possibility that changes in environmental quality may lead to changes in labor supply or goods demands by households that may — in aggregate — jointly determine environmental outcomes.

In contrast, it has been acknowledged at least since the early 1990s that one cannot ignore general equilibrium feedback responses in evaluating the economic costs of environmental regulations (Hazilla and Kopp, 1990). For example, the premise of the literature on second-best environmental taxation is that environmental regulations may discourage supply of basic factors of production, which are themselves subject to large, distortionary taxes. Thus, failing to account for these supply feedbacks may seriously understate the efficiency cost of a new environment regulation (Bovenberg and de Mooij, 1994).

The same logic could be applied to the measurement of benefits or - more broadly — to the 
enterprise of benefit-cost assessment of environmental policies if there was reason to believe that environmental impacts had the potential to interact with the broader economy in important ways. And the empirical literature on air-quality impacts has, in fact, identified specific candidates for such interactions. A number of recent, empirical studies document the linkages between air quality, health and various dimensions of human capital (Graff Zivin and Neidell, 2013). Researchers have documented meaningful impacts of particulate matter air pollution on worker productivity in both the agricultural sector — where on-the-job pollution exposure is expected to be high — in services industries - where it is not - and impacts on worker sick days in neighborhoods adjacent to polluting plants (Graff Zivin and Neidell, 2012; Chang et al., 2019; Hanna and Oliva, 2015).

While there are attempts incorporate these types of impacts into economy-wide models, the literature is still immature with no consensus on which impact channels are most important to represent in these models or established best practices for doing so.

The purpose of this review is to assess the existing literature on CGE models of air quality policies which attempts to include benefit-side feedback effects. In Section 2, we develop a unified theoretical framework to assess the nascent literature focused on incorporating air-quality impacts into general equilibrium models. In Section 3 applies our framework to the existing literature to identify areas or agreement or disagreement in model results and gaps in the study of different air-quality channels. In Section 4, we conclude by identifying priorities for future research in this field.

\section{A Unifying Framework for Studying CGE Air-Quality Impacts}

In this section, we develop a general equilibrium modeling framework describing the various channels through which changes in air-quality may influence the economy. We use this framework in subsequent sections of the paper to clarify how the various attempts to represent these channels in the existing literature relate to each other and to illustrate where new contributions may add value.

Consider a closed economy with $\mathcal{R}$ regions indexed by $r$. There are $\mathcal{H}$ types of heterogeneous 
representative consumers, indexed by $h$. These two dimensions of the framework capture acknowledged sources of heterogeneity in household responses to air quality. There is a strong spatial pattern of deposition for many local air pollutants. Thus, where a household is located determines to a large extent the damages they experience. Demographic characteristics (in particular, age and income) are also well-established determinants of damages; children and seniors face markedly higher mortality risks from criteria air pollutants (Gouveia and Fletcher, 2000; Ko et al., 2007).

\subsection{Consumption}

A representative household has the following expected utility function

$$
U_{r}^{h}=\sum_{t=0}^{\infty} \beta^{t} S_{t}^{h}\left(Q_{r}, x_{r}^{h}, l_{r}^{h}\right) u_{r t}^{h}
$$

where $\beta^{t}$ is the discount factor at age $t$ and $S_{t}^{h}$ is the probability a household, $h$, survives to age $t$. Survivorship depends on household demographics $(h)$, such as background mortality risk, as well as vectors of air pollution exposure $\left(Q_{r}\right)$, market goods $\left(x_{r}^{h}\right)$ and leisure time $\left(l_{r}^{h}\right)$ investments across the agent's lifetime. A household's instantaneous flow of utility in each time period is

$$
u_{r t}^{h}=u_{r}^{h}\left(x_{r t}^{h}, l_{r t}^{h} ; \theta_{r t}, q_{r t}^{h}\left(Q_{r t}, x_{r t}^{h}, l_{r t}^{h}\right)\right)
$$

where utility is a function of period consumption of a vector of market goods $\left(x_{r t}^{h}\right)$, leisure time $\left(l_{r t}^{h}\right)$, a vector of locational amenities other than air quality $\left(\theta_{r t}\right)$ and the effects of air quality itself $\left(q_{r t}^{h}\left(Q_{r t}, x_{r t}^{h}, l_{r t}^{h}\right)\right){ }^{1}$

\subsubsection{Channels of household impacts}

Making explicit the role of time in the determination of household well-being and pollution exposure is important because epidemiological evidence suggests that lifetime exposure (rather than contemporaneous exposure) determines the most serious health outcomes (Pope III and Dockery,

\footnotetext{
${ }^{1}$ For simplicity, we have abstracted from the possibility that a household's lifetime pollution exposure might be based on the pollution concentrations from multiple locations if they change where they reside mid-life. We discuss the role of household migration in the following section.
} 
1999; Pope III et al., 2002). Furthermore, baseline mortality risk is strongly determined by household age. Having noted these elements of the problem, we abstract from the time element in the discussion that follows to focus on the various contemporaneous channels through which air quality may impact household well-being.

The effects of air quality on household's utility can be modeled in different ways through a set of functions, $q_{r}^{h}$. First, the level of air pollution may enter the utility function directly as a source of hedonic pleasure for households,

$$
q_{r}^{h}=f\left(Q_{r}\right), \frac{\partial f}{\partial Q_{r}} \leq 0
$$

Low visibility, unpleasant odors or the unpleasant sensation of breathing in polluted air are all examples of this type of impact.

Second, air quality may combine with other goods and services as a substitute or complement to produce goods and services that are of direct value to consumers. For example, air quality may be a substitute for watching a movie (an indoor activity) in the production of entertainment. It may be a complement to leisure time in the production of going for an enjoyable hike.

Within the class of impacts in which air quality functions as an input to the production of some final source of value to consumers, there are a number of specific categories of interest that are worth considering separately. Air pollution may impact the value of other non-use $(v(\cdot))$ and use $(e(\cdot))$ goods and services,

$$
\begin{gathered}
q_{r}^{h}=v_{r}^{h}\left(Q_{r}\right), \frac{\partial v_{r}^{h}}{\partial Q_{r}} \leq 0 \\
q_{r}^{h}=e_{r}^{h}\left(Q_{r}, x_{r}^{h}, l_{r}^{h}\right), \frac{\partial e_{r}^{h}}{\partial Q_{r}} \leq 0 .
\end{gathered}
$$

For example, acid rain destroys ecosystems and corrodes historical buildings, which may hold either use or non-use values.

Non-use values - by definition — produce no behavioral signal in consumers' observable consumption patterns. That is, they are separable from the other arguments in the household's preference function, i.e., equations (3) and (4). Use value, on the other hand, may interact with market 
goods and services. For example, if degradation of fishing quality in wilderness areas impact by acid rain causes household to spend less time on fishing trips, we may observe a reduction in the demand for leisure time, i.e., equation (5).

Finally, there are a variety of impacts on human health. Following Williams III (2003), one can model the impacts of environmental quality change and medical care on health and time endowment. Air quality and medical care (this may also include other goods and services used to avoid and mitigate exposure to air pollution), $m^{h}$, enter into a household's health production function

$$
q_{r}^{h}=h_{r}^{h}\left(m_{r}^{h}, Q_{r}\right)
$$

Health status is a negative function of air pollution and positive function of medical care. It also affects the enjoyment of commodities and leisure, i.e., $\frac{\partial h}{\partial m} \geq 0, \frac{\partial h}{\partial Q} \leq 0, \frac{\partial^{2} u}{\partial x \partial h} \leq 0$, and $\frac{\partial^{2} u}{\partial l \partial h} \leq 0$.

Health status may also affect the amount of time a household can devote to work or leisure. The time constraint of a representative household $h$ in region $r$ is

$$
T_{r}^{h}-s_{r}^{h}\left(m_{r}^{h}, Q_{r}\right)=L_{r}^{h}+l_{r}^{h}, \frac{\partial s^{h}}{\partial m_{r}^{h}} \leq 0, \frac{\partial s^{h}}{\partial Q_{r}} \geq 0
$$

where $T_{r}^{h}$ is total time endowment, $L_{r}^{h}$ is the quantity of labor supply, and $s_{r}^{h}$ represents pollutioninduced sick time. While $s_{r}^{h}$ and $h_{r}^{h}$ are both related to health status, $h_{r}^{h}$ emphasizes the direct impact of illness on utility while $s_{r}^{h}$ focuses on time allocation. Time loss due to illness can be avoided or mitigated by medical treatments. Reducing air pollution will increase time availability for both labor and leisure.

A representative household's monetary budget constraint is

$$
p^{x}\left(1+\tau_{r}^{x}\right) \hat{x}_{r}^{h}+p^{m}\left(1+\tau_{r}^{m}\right) m_{r}^{h}+p_{r}^{H}\left(1+\tau_{r}^{H}\right) H_{r}^{h}=w_{r}^{h}\left(1-\tau_{r}^{L}\right) L_{r}^{h}+p_{r}^{N}\left(1-\tau_{r}^{N}\right) N_{r}^{h}+G_{r}^{h}
$$

where $p^{x}$ is the price vector of market goods that are freely trade across regions. Thus, the law of one price holds. Let $\hat{x}_{r}^{h}$ represent the vector of a household's consumption levels of these traded goods. Medical care may be traded as well and thus is offered at price $p^{m}$, but it is represented here 
separately to emphasize its special role in the production health. Housing markets are regional, thus the rental price of housing is $p_{r}^{H}$ and demand for housing is $H_{r}^{h}$. To connect our discussion here to $(2)$, let $x_{r}^{h} \equiv\left\{\hat{x}_{r}^{h}, m_{r}^{h}, H_{r}^{h}\right\} . w_{r}^{h}$ is the local wage rate. $\tau_{r}^{x}, \tau_{r}^{m}, \tau_{r}^{H}$ and $\tau_{r}^{L}$ represent regional tax rates on our various goods categories and labor respectively. $G_{r}^{h}$ denotes government transfers.

The left-hand side of (8) captures the monetary assets the household has at its disposal to cover its expenses. In the discussion that follows, it is also useful define full income as the the value of the household's monetary assets plus the value of it's available time budget. Thus full income is defined as

$$
M_{r}^{h} \equiv w_{r}^{h}\left(1-\tau_{r}^{L}\right)\left(T_{r}^{h}-s_{r}^{h}\left(m_{r}^{h}, Q_{r}\right)\right)+p_{r}^{N}\left(1-\tau_{r}^{N}\right) N_{r}^{h}+G_{r}^{h}
$$

\subsection{Migration}

At a point in space, no individual household has the ability to influence ambient air quality; air quality is quasi-fixed. However, households can select air quality level by choosing where to live. Here we borrow the logic of residential sorting models to capture this element of equilibrium responses to changes in regional air quality (Kuminoff et al., 2013).

Let $V_{r s}^{h}\left(p_{r}, w_{r}^{h}, \tau_{r}, G_{r} ; \theta_{r}, q_{r}^{h}\left(Q_{r}\right), p_{s}, w_{s}^{h}, \tau_{s}, G_{s} ; \theta_{s}, q_{s}^{h}\left(Q_{s}\right)\right)$ denote the maximum (indirect) utility of a representative household $h$ from region $r$ can obtain in region $s$ given the prices of goods services both tradable and non-tradable), wage rate, taxes, government transfers and local amenities $\left(\theta_{s}\right.$ and air quality effects $\left(q_{s}^{h}\right)$ in region $s$. Thus, following the notation developed in $(1), V_{r s}^{h}$ is the solution to the problem

$$
\max _{x^{h}, l^{h}} \sum_{t=0}^{a-1} \beta^{t} S_{t}^{h}\left(\sum_{u=0}^{a-1} Q_{r u}\right) u_{r t}^{h}+\sum_{t=a}^{\infty} \beta^{t} S_{t}^{h}\left(\sum_{u=0}^{a-1} Q_{r u}+\sum_{u=a}^{t} Q_{s, u}\right) u_{s, t}^{h}
$$




$$
\begin{aligned}
& \text { s.t. } \sum_{t=0}^{a-1} p_{t}^{x}\left(1+\tau_{r t}^{x}\right) \hat{x}_{r t}^{h}+p_{t}^{m} m_{r t}^{h}+p_{r t}^{H}\left(1+\tau_{r t}^{H}\right) H_{r t}^{h} \\
& +\sum_{t=a}^{\infty} p_{t}^{x}\left(1+\tau_{s, t}^{x}\right) \hat{x}_{s, t}^{h}+p_{t}^{m} m_{s, t}^{h}+p_{s, t}^{H}\left(1+\tau_{s, t}^{H}\right) H_{s, t}^{h} \\
& =\sum_{t=0}^{a-1} w_{r t}^{h}\left(1-\tau_{r t}^{L}\right) L_{r t}^{h}+G_{r t}^{h}+\sum_{t=a}^{\infty} w_{s, t}^{h}\left(1-\tau_{s, t}^{L}\right) L_{s, t}^{h}+G_{s, t}^{h} \\
& T_{r t}^{h}-s_{r t}^{h}\left(m_{r t}^{h}, Q_{r t}\right)=L_{r t}^{h}+l_{r t}^{h}, \forall t \in\{0, \ldots, a-1\} \\
& T_{s, t}^{h}-s_{s, t}^{h}\left(m_{s, t}^{h}, Q_{s, t}\right)=L_{s, t}^{h}+l_{s, t}^{h}, \forall t \in\{a, \ldots, \infty\}
\end{aligned}
$$

if a household were to move from $r$ to $s$ at age $a$.

We assume $\left(-m c_{r s}^{h}\right)$ is the negative utility associated with moving from the original location $r$ to another location $s$. Bayer et al. (2009) emphasize the necessity of including moving costs while evaluating the willingness to pay for air quality. The household maximizes utility by choosing the alternative location with the highest overall utility

$$
\max _{s}\left\{V_{r s}^{h}-m c_{r s}^{h}\right\}
$$

Let

$$
i_{r s}^{h} \equiv \begin{cases}\omega_{r}^{h} & \text { if } V_{r s}^{h}-m c_{r s}^{h}=\max _{q}\left\{V_{r q}^{h}-m c_{r q}^{h}\right\} \\ 0 & \text { otherwise }\end{cases}
$$

where $\omega_{r}^{h}$ is the measure of households of type $h$ originating at $r$ (such that $\sum_{r, h} \omega_{r}^{h}$ is the population of the economy.)

\subsection{Production}

Air quality also affects the production of commodities. Air pollution has direct impact on production sector through labor productivity, natural inputs, and capital depreciation as well as indirect impact though labor and capital markets. We assume each representative firm produces one of $\mathcal{I}$ 
goods, indexed by $i$. The production function of a firm is

$$
y_{r}^{i}=f\left(x_{r}^{i}, L_{r}^{i}, N_{r}^{i} ; \theta_{r}, Q_{r}\right)
$$

where $y_{r}^{i}$ is the output level of sector $i$ in region $r, x_{r}^{i}$ is a vector of intermediate input demands for sector $i$ in region $r, L_{r}^{i}$ is labor inputs and $N_{r}$ inputs of land and other forms of capital. As before, $Q_{r}$ indicates the level of air pollution in $r$ and $\theta_{r}$ is a vector of other amenities.

Assuming firms are cost-minimizers, we can write a representative firm's total cost function as $C_{r}^{i}\left(p_{r}, w_{r}, r_{r} ; Q_{r}, y_{r}^{i}\right)$ where $r_{r}$ denotes the rental rate of land or other forms of capital.

The level of air pollution is a function of dirty goods output,

$$
Q_{r}=g\left(y_{r}\right)
$$

where $y_{r}$ is the vector of sectoral output levels in $r$, and $\frac{\partial g}{\partial y_{r}^{i}} \geq 0, \forall i$. Other than increasing the tax on dirty goods, government can control air pollution through the $g$ function, such as setting upper limit of emission and requiring higher environmental standards for firms.

Air pollution affects production through the following channels. First, labor productivity is negatively affected by air pollution, thus $\frac{\partial^{2} y_{r}^{i}}{\partial L_{r}^{i} \partial Q_{r}}<0$.

Second, in a dynamic framework, the depreciation of capital depends on air pollution so that the law of motion for capital is

$$
N_{r, t+1}=\left(1-d\left(Q_{r t}\right)\right) N_{r t}+I_{t}
$$

where $d\left(Q_{r t}\right)$ is the depreciation rate, with $d_{Q}>0$, and $I_{t}$ is investment in the previous period.

Third, in agricultural and forestry sectors, in addition to its impact on labor, $Q_{r}$ enter into the production function directly as one of the inputs and negatively affect the yields of plants.

Finally, firms will relocate to place with the highest net present value of profit - conditional on moving costs - in a process that parallels the migration of households (Nakosteen and Zimmer, 1987). A firm that currently produces good $i$ at location $r$ would have the following profit function 
if it had moved to region $s$

$$
\pi_{r s}^{i}\left(p, w_{s}, r_{s} ; \theta_{s}, Q_{s}\right)
$$

At time $t$, a firm will react to the changes in factor price, wage rate, land price, and air quality by relocating to region $s$ to maximize the present value of profit

$$
P V_{r s, t}^{i}=\left(\sum_{t}^{\infty} \beta^{t} \pi_{r s}^{i}\right)-m c_{r s, t}^{i}
$$

where $\beta$ is shareholders' discount factor and $m c_{r s, t}^{i}$ is moving cost of the firm. On one hand, firms prefer location with low level of pollution so that the input factors are less impacted and capital depreciates slower. On the other hand, region with higher level of pollution may have low price of land and slack pollution regulation which implies less constraint on production.

\subsection{Government}

A regional governments' revenue equals to expenditure

$$
\sum_{h}\left(p_{r} \tau_{r} X_{r}^{h}+w_{r}^{h} \tau_{r}^{L} L_{r}^{h}\right)=\sum_{h} G_{r}^{h}
$$

We can also introduce government policies other than consumption taxation and lump sum transfer. The most relevant policies in this case are air quality controls. When dealing with multiregional affairs, a federal government is needed.

\subsection{General Equilibrium}

Having the model dimensions and the motives ascribed to the different model agents, what remains is to describe how equilibrium prices are determined. We assume that all consumers and firms and price-takers and markets clear as conceived of in the model of competitive equilibrium. Mathiesen (1985) demonstrated that general equilibrium models may be formulated as complementarity problems and we follow this approach in the discussion that follows. Mathiesen's approach consists of defining three types of pairings between model equations and variables in complementary 
slackness conditions. Zero-profit conditions are associated with the activity levels of producers in each economic sector. Market-clearance conditions are paired with the price variables that adjust to ensure and supply equals demand. Income-balance conditions ensure that all households obey their resource constraints.

For each economic sector, $i$, the representative firm will supply up to the point where the marginal cost of production just equals the output price. The sector is inactive $\left(y_{r}^{i}=0\right)$ if marginal cost everywhere exceeds the output price.

$$
\frac{\partial C_{r}^{i}}{\partial y_{r}^{i}} \geq p_{r}^{i} \perp y_{r}^{i} \geq 0
$$

where the " $\perp$ " indicates a complementary-slackness relationship.

For each market upon which goods and services are traded, supply and demand must equalize. If the good in question is traded across all regions, then this becomes

$$
\sum_{r} y_{r}^{i} \geq \underbrace{\sum_{r} \sum_{h} \frac{\partial V_{r}^{h}}{\partial p^{i}} / \frac{\partial V_{r}^{h}}{\partial M_{r}^{h}}}_{\text {Final }}+\underbrace{\sum_{r} \sum_{j} \frac{\partial C_{r}^{j}}{\partial p^{i}}}_{\text {Intermediate }} \perp p^{i} \geq 0 .
$$

If the good in question is regional, then the market-clearance condition becomes

$$
y_{r}^{i} \geq \underbrace{\sum_{h} \frac{\partial V_{r}^{h}}{\partial p^{i}} / \frac{\partial V_{r}^{h}}{\partial M_{r}^{h}}}_{\text {Final }}+\underbrace{\sum_{j} \frac{\partial C_{r}^{j}}{\partial p^{i}}}_{\text {Intermediate }} \perp p_{r}^{i} \geq 0 .
$$

The expressions for intermediate demands in (19) and (20) employ Shephard's lemma, and the expressions for final demands make use of Roy's identity, where $M_{r}^{h}$ is full income, as defined in $(9)$.

Migration enters the equilibrium by determining regional labor supply and housing demand. For a given household, labor supply is defined as

$$
L_{r}^{h} \equiv T_{r}^{h}-s_{r}^{h}\left(m_{r}^{h}, Q_{r}\right)-\underbrace{\frac{\partial V_{r}^{h}}{\partial w_{r}^{h}} / \frac{\partial V_{r}^{h}}{\partial M_{r}^{h}}}_{\text {leisure demand }} .
$$


Then aggregate labor supply at $r$ is $L S_{r} \equiv \sum_{h} L_{r}^{h} \sum_{s} i_{s r}^{h}$. And the labor market clearance condition becomes

$$
L S_{r} \geq \sum_{i} \frac{\partial C_{r}^{i}}{\partial w_{r}} \perp w_{r} \geq 0
$$

where the right-hand side of the equation indicates aggregate labor demand across all sectors. ${ }^{2}$

Similarly, regional housing markets equate supply and demand for housing, where demand for housing is derived from the household optimization problem and the size of the regional population.

$$
y_{r}^{H} \geq \sum_{h} \frac{\partial V_{r}^{h}}{\partial p_{r}^{H}} / \frac{\partial V_{r}^{h}}{\partial M_{r}^{h}} \sum_{s} i_{s r}^{h}+\sum_{i} \frac{\partial C_{r}^{i}}{\partial p_{r}^{H}} \perp p_{r}^{H} \geq 0 .
$$

\section{Current literature}

This section summarizes how the recent studies, as listed in Table 1, incorporate the various effects of air quality change in general equilibrium. We apply the framework developed in the previous section to demonstrate how the different health and non-health linkages between environment and economy are modeled with different techniques and structures in applied researches. Most of the literature focuses on evaluating the welfare change of a shock to the environmental quality (e.g., Carbone and Smith, 2013; Zhang et al., 2017). Some studies analyze the consequences of environmental regulation for macroeconomic performance ${ }^{3}$ (e.g., Vennemo, 1997; Vrontisi et al., 2016). Despite the differences in the precise research questions addressed, the approaches taken by authors to the design of the economy-wide models employed in their analyses share many common features.

Most modeling efforts begin with an effort to translate emissions of pollutants from economic activities into concentrations and then the exposure to the agents in a economy. Some studies, however, simply model an environmental quality change as exogenous shock to an economy with no feedback from the economy back to the environment (e.g., Saari et al., 2015; Vrontisi et al., 2016). More sophisticated models capture the environment endogenously so that environmental

\footnotetext{
${ }^{2}$ In the aim of simplicity, we have assumed here that there is a common pool of labor across all worker types and sectors. However, one could easily accommodate labor markets that are segmented by sector or worker type as well.

${ }^{3}$ Smith (2012) points out the importance of incorporating environment in macroeconomic analysis.
} 
quality is determined by the economic activities in the model (e.g., Espinosa and Smith, 1995; Vennemo, 1997; Li, 2002; Carbone and Smith, 2008; Mayeres and Regemorter, 2008; Carbone and Smith, 2013; Smith and Zhao, 2016). They either use a set of equations to model the air pollution emission and transportation process, as in (13), or link a CGE model to external emissions and population models.

Another important modeling choice centers around the human impacts of pollution exposure. There are extensive literatures on both the dose-response functions that translate pollution exposure into physical outcomes for humans and on recovering human preferences (willingness to pay) to avoid exposure — both of which represent critical inputs into CGE modeling exercises in this domain. However, they are outside the scope of this review.

Similarly, as our focus is on how to incorporate the benefit-side impacts of air quality improvement, we omit any discussion of technical aspects of CGE modeling — such as calibration — that are not directly connected to the modeling of air quality impacts. (See Wing (2011) for a summary of the procedures of modeling economy-environment interactions in CGE models and examples of implications.

\subsection{Health Effects}

Due to the fact that health effects loom large in most benefit-cost analysis of major air regulations, it is unsurprising that these channels have received the most attention in the CGE literature to date. An extensive set of epidemiological studies have documented the mortality and morbidity effects of many air pollutants on human beings. US EPA (2011) provides a comprehensive summary of the results from these studies. It is standard practice in the evaluation of air regulations to apply these epidemiological estimates to affected populations and monetize these impacts by multiplying the implied change in the mortality rates, for example, by an average willingness to pay measures derived based on the value of a statistical life. Less common in the literature is the practice of incorporating the health effects into households' behavioral responses by modifying the structure of the utility function and introducing separable or non-separable air quality components.

Researchers have also used changes in air quality (and the health impacts) to update the con- 
straints on the resources households can allocate. These methods allow for the possibility of modeling a variety of different interactions among market and non-market goods in a general equilibrium. The following subsections outline these approaches.

\subsubsection{Health Status and Monetary Budget Interactions}

To model the utility derived from health, researchers frequently introduce a new good — here we call it health services/health status. Practically, researchers either modify the utility function by inserting a nested component or by introducing a new production sector that takes medical services, air quality, and possibly other goods as inputs to produce the health service (Yang et al., 2005; Matus et al., 2008; Selin et al., 2009; Nam et al., 2010; Matus et al., 2012; Carbone and Smith, 2008; Mayeres and Regemorter, 2008; Saari et al., 2015; Smith and Zhao, 2016). From the perspective of theory, these two methods are equivalent.

It is common that health status is a function of both market (e.g., medical services and other goods that are used to avoid or mitigate air pollution exposure) and non-market goods — as shown in equation (6) - and enters utility non-separably, as shown in equation (2). Therefore, health status will affect a household's consumption and time allocation decisions through the utility function. For example, the health status as a whole may be a complement to other goods and leisure (Yang et al., 2005). A good health status can be necessary for physical activities such as traveling.

The health status can also be modeled separably from other goods; its level affects the overall utility derived from other goods but does not change the ordering of these goods (Vennemo, 1997; Mayeres and Regemorter, 2008). Espinosa and Smith (1995) model the welfare loss due to mortality in this way. The principal benefit of such an approach is simplicity - fewer preference parameters will be needed and calibration is straightforward. The principal shortcoming of this assumption is that any interaction between health status and commodities that may exist will not be captured in the model.

In the production function of health status, medical services and air quality are assumed to be substitutes. For a given level of health status, less medical services are needed if there is an improvement in air quality. While writing out the budget constraint, we explicitly list the 
corresponding medical expense in equation (8) to emphasize the fact that an improvement in air quality reduces medical expenses, relaxing the budget constraint on all other goods. The income effect will increase the consumption of normal goods and improve utility. ${ }^{4}$ Similarly, government spending on medical services, such as the Medicaid and Medicare programs in the US, other forms of subsidies and insurance, can be reduced and achieve the same target health level. Households will benefit from direct tax cut or increase in other government transfers (Espinosa and Smith, 1995; Li, 2002; Mayeres and Regemorter, 2008; US EPA, 2011; Vrontisi et al., 2016).

\subsubsection{Time Allocation and Labor Productivity}

Several specifications have been employed in the literature to represent the morbidity and mortality effects on time allocation. First, within the framework of the MIT Emission Prediction and Policy Analysis-Health Effects (EPPA-HE) model (Yang et al., 2005; Matus et al., 2008; Selin et al., 2009; Nam et al., 2010; Matus et al., 2012), the United States Regional Energy Plicy (USREP) model (Saari et al., 2015), and the China Regional Energy Model-Health Effect (CREM-HE) model (Zhang et al., 2017), researchers introduce household labor, in addition to medical services and market goods, into the production of health services. The idea is that the suffering of illness, hospital admission, and recovering from sickness will reduce the time endowment that is available for both labor and leisure.

A number of other studies do not model health production explicitly but include leisure as a non-separable component in the utility function (Vennemo, 1997; Carbone and Smith, 2008; Selin et al., 2009; US EPA, 2011; Carbone and Smith, 2013; Saari et al., 2015; Vrontisi et al., 2016; Smith and Zhao, 2016). With this preference structure, the supply of labor derived from utility maximization is conditional on the level of air quality and the quantity of market goods. Therefore, even though the later group of papers does not explicitly specify the impact of air pollution on health effects, they still capture the impact on time allocation and labor supply indirectly.

A second approach is to incorporate morbidity or mortality related time effects in the time constraint as a function of medical expense and pollution exposure as shown in (7). The total

\footnotetext{
${ }^{4}$ The increase in leisure due to the income effect is a negative effect with pre-existing labor tax.
} 
amount of time available for work and leisure is conditional on a household's health status. (Mayeres and Regemorter, 2008), (US EPA, 2011), (Carbone and Smith, 2013), (Vrontisi et al., 2016) and (Zhang et al., 2017) all employ this method. In contrast to the first method, this method only captures the income effects due to the relaxing of the time constraint and and budget constraint (increase in labor income) and rules out any substitution effects.

Third, researchers have modified the production function or the marginal product of labor to make them conditional on air quality. Mayeres and Regemorter (2008) model the labor component in a CES production function as $\left(L(1-\gamma(Q))^{\sigma}\right.$ where $\sigma$ is elasticity of substitution among inputs and $\gamma$ measures percentage losses in productivity or working day which is a increasing function of air pollution. In the short term (in terms of labor market adjustments), a worker's contract may pay her for the effective labor supplied as well as sick days. That is, households receive the same payment as prior to a pollution shock, however firms need to hire more labor or substitute with other production factors to produce the same amount of total outputs. In the long term, when markets are able to adjust to reflect the true productivity in the wage, households will be paid with a lower wage rate than the wage before a pollution shock. Vennemo (1997) directly multiplies the real wage rate by a productivity parameter to capture the productivity change due to pollution related health damage. Researchers also adjust the labor supply which will in turn affect wage rate and households' time allocation (Li, 2002; Yang et al., 2005; Matus et al., 2008; Selin et al., 2009; Nam et al., 2010; US EPA, 2011; Matus et al., 2012; Saari et al., 2015).

From the perspective of theory, the time endowment method is equivalent to the wage (labor productivity) method since the full income from time endowment is equal to $w(L+l)$ where leisure is valued at wage rate and households can choose as much leisure as they want (guided by certain preference). A change in time $L+l$ can be translated to change in wage $w$.

It is far less common for children and senior to be explicitly represented in these models despite their elevated health risks relative to prime-aged adults. An existing way of capturing welfare loss due to their illness is valuing their time loss at discounted wage rate (Yang et al., 2005; Matus et al., 2008).

All of the techniques mentioned in this section fall into the category of time endowment or 
human capital approaches which evaluate the pollution induced time loss and deaths at the wage rate. Notably, estimates of willingness to pay to avoid mortality risks which are derived from empirical and partial equilibrium (PE) analyses (such as the VSL approach) are much larger than the welfare effects generated by the human capital method employed in the CGE literature when the same change in baseline mortality risk is applied to both models (REF?). We discuss more on this issue with the survivorship in section 4.1.

\section{$3.2 \quad$ Non-Health Environmental Benefits}

Relative to health effects, researchers have spent considerably less effort on the modeling of nonhealth effects. Nevertheless, there may be important candidates in this category to consider in terms of magnitude and their feedbacks on an economy, especially to the degree the non-separability between market goods and ecosystem services.

\subsubsection{Non-Use Values}

Household may hold non-use or existence values for cleaner air or better ecosystem health. Technically, the utility derived from these types of values do not interact with market goods and leisure so that they can be modeled separably. As an example of an early effort to incorporate the environment into general equilibrium model, Vennemo (1997) assumes all of the direct utility related welfare change associated with environmental quality, such as the acidification of lakes and forest, are separable from market goods and does not affect households' decision making in addition to income effects.

To model the separable utility of a set of goods, researcher have often employed an additive separable structure. Mayeres and Regemorter (2008), for example, include a sum over the values of air pollutants valued at marginal utilities that correspond to a household's marginal willingness to pay for the effects other than morbidity induced time loss and health status. In other words, this separable component consists the negative utility of mortality and all non-health effects. Other researchers have also adapted a constant elasticity of substitution (CES) function in which the substitution pattern of the environmental goods within a sub-nest is independent of the goods that 
are not included in the sub-nest. Carbone and Smith (2013) use this method to model the existence value of ecosystem. ${ }^{5}$

\subsubsection{Use Values}

Air pollution damages ecosystems, which provide valuable sites for outdoor activities. In addition to damage to lakes and trees, bad air quality itself will also prevent people from accessing sites for leisure activity, altering consumption and time allocation decisions. These impacts on consumer behavior and the tourist industry make it meaningful to model environmental quality using nonseparable methods in general equilibrium. (Carbone and Smith, 2008) and (Carbone and Smith, 2013) use a nested utility structure to model the non-separability between leisure, an air quality component, and market goods. When these three arguments are complements within a same subnest, the structure models the consumer's ability to combine leisure and certain market goods as well as the environment to undertake recreational activities. With the non-separable structure, the consumption pattern of leisure and the market goods within the sub-nest is conditional on the level of air quality. As we noted in section 3.1.2, this interaction will also influence labor supply.

\subsubsection{Capital Productivity and Depreciation}

Air pollution, especially in the form of acid rain, damages lands, buildings, roads, and other types of capital that are used in production. It also reduces the yields of crops and forests. Vrontisi et al. (2016) increase the productivity of the agricultural sector to reflect the increase in crop yields as a benefit of air quality regulation. Vennemo (1997) is the only study that assumes building, as an input of production, depreciates at a rate that is an increasing function of $\mathrm{SO}_{2}$ emission in its dynamic model, as we show in equation (13). When households own land, forests and buildings, higher productivity and increased stocks of these natural assets also increase household income.

\footnotetext{
${ }^{5}$ Because both forms are separable, change in air quality has no consequences for the behavioral responses in the model. However, it is worth noting that the two methods have the potential to yield different welfare measurements for same change in air quality. An increase in air quality under the additive approach has no effect on the marginal utility of consumption of other goods and services whereas the CES approach does through its multiplicative form.
} 


\subsection{Household Migration}

Although it is common that the CGE models in the literature disaggregate the global economy (Espinosa and Smith, 1995; Mayeres and Regemorter, 2008; Selin et al., 2009) or a national economy into subregions (US EPA, 2011; Saari et al., 2015; Zhang et al., 2017; Giesecke and Madden, 2017), little attention has been paid to household migration, an important avoidance response to pollution exposure. All the channels described listed in sections 3.1 and 3.2 affect households' health status, prices of market goods, wage rate and consequently households' expected utility and migration decisions.

Giesecke and Madden (2017) is the only study, to our knowledge, that attempts to model household migration as a response to local amenities. They use a multi-regional dynamic CGE model of the Australian economy called Victoria University Regional Model (VURM). In this model, households make migration decisions by comparing local real wage and employment rate of the regions as well as taking location preferences into account. They define a migration income as the product of real wage rate and employment rate. As a result, the migration rate between any two regions is a function of the change in the relative incomes the household could obtain in the origin and destination regions. The authors assume the functional form to be inverse logistic to model heterogeneous preferences of residential location, autonomous migration trend (the migration rate without any exogenous shock), and historical upper and lower boundaries of migration rate. To model the local amenity induced migration, they impose a shock to the relative migration income which intends to capture the compensation of amenity change in terms of migration income. The VURM model itself does not value the welfare of amenity change, instead, exogenous non-market valuation is needed to link the change in amenities to migration flows. We continue this discussion in section 4.3 .

\section{Research Challenges}

This section summarizes the effects of air pollution that receive little or no attention in the literature to date and lays out a path for future research. 


\subsection{Mortality Risk}

As noted in equation (1) from our framework, perhaps the most basic way in which human health is impacted by air quality is through its effects on mortality rates. The large majority of the benefits registered in benefit-cost analyses of major air regulations stems from VSL-based calculations of avoided mortality risk. It is somewhat ironic, therefore, that none of the studies in the existing literature — despite the heavy emphasis there on modeling health effects — has tackled this channel.

There are important shortcomings to the "time-endowment approach" to capturing damages associated with mortality risk that is prevalent in the CGE-based literature and discussed in section 3.1.2. As we have noted, the estimates of the avoided damages from models employing this technique are orders of magnitude smaller than those produced by the partial equilibrium, VSL-based method that is the standard in benefit-cost analysis of air regulations. This is not to suggest that the VSLbased approach is without its own flaws, but there is an obvious difference in the approaches that is capable of explaining the discrepancies. The time-endowment approach assumes that the only source of benefit household derive from reduced mortality risk is recovery of the wages lost from attrition of the workforce due to mortality. It is difficult to argue that the investments we all make in longevity are driven simply by the desire to collect additional paychecks. Therefore, it seems certain that this approach will vastly underestimate true consumer surplus associated with the change in mortality risk. ${ }^{6}$

The PE-VSL-based approach has drawbacks as well. VSL measures are theory-consistent measures of a consumer's marginal willingness to pay to avoid a small increase in mortality risk. To arrive at a total damages estimate, however, this marginal measure is applied to discrete changes in mortality risk associated with the policies under evaluation with no adjustment. Doing so risks overstating true willingness-to-pay by ignoring the logic of downward-sloping demand curves; subsequent improvements in mortality risk should be less valuable on the margin than initial units. Moreover, part of what drives this shape of the demand curve is the fact that households have limited budgets and the VSL approach ignores these types of resource-constraint issues.

For these reasons, a hybrid approach which takes the best of both modeling strategies seems

\footnotetext{
${ }^{6}$ See US EPA (2017), Section 4.2.
} 
warranted. CGE models are designed to capture a full set of resource constraints, so embedding the logic of the VSL by including a full description of the change in survival risk as described in (1) seems like a promising approach. However, implementing such a strategy has a few challenges. First, modeling survivorship requires either an explicitly dynamic model or — at the very least — one that models the life cycle of households. Many models in the current literature are static in nature as adding dynamics inevitably increases the dimensionality of a model. Second, one must develop a strategy for calibrating household preference functions to reflect empirical estimates of willingness to pay to avoid mortality risk, such as VSL estimates. While there are no examples of existing CGE models which undertake this task, there are examples of numerical experiments in which preference functions are calibrated to VSL information in a theory-consistent way (Murphy and Topel, 2006; Jones and Klenow, 2016).

Despite the technical and conceptual challenges, the payoffs to tackling these issues seem substantial. The importance of mortality risk in current benefit-cost assessments of air regulations is self-evident. Beyond this, the central role of mortality risk in life cycle consumption choices would seem to make it an important driver of long-term economic performance. The theory of life-cycle consumption predicts that investment should depend on the long-term economic outlook. More specifically, an individual's decision to invest in human and other forms of capital should depend on life expectancy as increased longevity raises the potential to capture the return on that investment. These effects could be particularly important in determining the lifetime net benefits of air regulations because of the persistence of capital investments in shaping future economic performance.

\subsection{Demographic and Spatial Heterogeneity}

As we emphasized at the outset, demographic and spatial heterogeneity in exposure to pollution, baseline risk and willingness to pay to avoid pollution-related risks are all empirical facts with which quantitative analyses of air regulations must grapple.

Most of the current CGE-based studies only model a single representative household for each region represented in the model. There are three exceptions. Li (2002) models three types of 
households (agricultural, non-agricultural, and government-employed) with different preference, income level, and air pollution exposure. US EPA (2011) and Saari et al. (2015) model 4 and 9 groups of representative households by annual income respectively.

Once again, the curse of dimensionality poses a modeling challenge in this regard. Nevertheless, it seems important, in particular, to move in the direction of models with explicit representation of agents of different ages in light of the character of the mortality impacts. Within the CGE literature, dynamic models with an overlapping generations structure seem best suited to taking on this task. These models represent households which summarize different generations and which follow life-cycle consumption paths based on finite life lengths. Thus, the logic of mortality impacts could be incorporated into this framework in a natural way.

Describing sufficient spatial detail of impacts in CGE models poses similar challenges. Current PE-VSL-based approaches for measuring air pollution damages take counties as the spatial unit of analysis (for US-based studies). In part, this is because the data and computational requirements associated with this approach are modest compared to CGE analysis. However, this modeling choice also reflects the judgement in the literature that the nexus of heterogeneity in exposure and demographic-driven risk across space is a fundamental aspect of the problem at hand. In contrast, CGE model are typically specified at the level of national or global economies. At most, they have state-level detail.

\subsection{Spatial Sorting}

Ultimately, judging how important spatial detail in equilibrium models of air quality impacts is for aggregate welfare analysis depends on the extent of the regional labor and housing markets into which air quality benefits are capitalized. This, in turn, depends on the extent to which households choose where to live based on access to environmental amenities, so that regional wages and housing rental rates reflect the value of local air quality. In this regard, the evidence suggests that "space matters." Bayer et al. (2009) demonstrate that accounting for barriers to migration is critical to the enterprise of recovering household preferences for avoiding particulate matter (PM) based air quality; they find that estimates of willingness to pay for reduction in PM pollution are an order 
of magnitude larger than comparable estimates from models that assume households freely choose their place of residence in response to relative prices for housing and labor.

This suggests that CGE modelers working in this domain need to look for ways not only to add spatial detail to their models but also to work towards incorporating a better empirical foundation for describing the flow of people across space. Some marriage of CGE analysis with the insights of locational equilibrium models as described in Kuminoff et al. (2013) seems warranted. We provide an illustrative example in section 2.2. Conceptually, rational households choose location to reside in two steps. First, they maximize the attainable utilities of each potential place by choosing market goods and the amount of leisure, given the quasi-fixed local public goods, i.e., consumer's problem (10). In the second step, they choose the residential location with the highest utility net off the moving costs, i.e., consumer's problem (11). In general equilibrium, the consequent impacts of households' decision making on local labor supply and housing demand are collectively reflected in conditions (21) and (22) respectively ${ }^{7}$.

What exact form this approach takes, however, remains to be seen. Locational equilibrium models are able characterize demographic and spatial detail at much finer resolutions than CGE models. What is needed, therefore, are sound methods for developing summary statistics which communicate the key insights of locational equilibrium models for economy-wide outcomes.

\subsection{Non-Market Valuation for Economy-Wide Analysis}

A related consideration is establishing a better empirical foundation for the linkages between changes in air quality and the typical behavioral responses captured by CGE models. Many of the theoretical channels we have described in this domain imply relationships between air-quality and marketed goods and services as substitutes or complements in the production of human wellbeing, e.g., equation (5). CGE analysis of these relationships requires that the researcher choose values for the elasticities of substitution that determine their strength.

Obtaining an empirical foundation on which to base the values is a challenge for at least two

\footnotetext{
${ }^{7}$ In our framework, households sorting indirectly affects local pollution levels through labor and housing/land markets since firms that produce dirty goods react to the changes in factor prices by sorting across locations. In addition, the dynamic of population influences governments' fiscal policies and providing of public goods. It is also likely that household consumption impacts air quality, such as the using of energy.
} 
reasons. Once again, the units of analysis differ so widely across the empirical literature and CGE analysis. The non-market valuation studies that are designed to recover preferences for environmental good and services typically work at a much finer spatial scale — both to establish the degree of variation on the data that is required to identify the key parameters of interest, and because, historically, the domain of interest for these studies has been developing measures of local environmental damages.

A second, perhaps more fundamental, challenge arises from the fact that non-market valuation research designs often use assumptions about the relationship between the environment and marketed goods and services to establish empirical identification. Thus, the elasticities of substitution that are of interest to CGE analysis are maintained assumptions in these models.

As a result, it seems certain that CGE analyses must move closer to meeting the empirical literature at these finer spatial scales and - at the same time - the empirical literature must evolve to develop research designs suited to capturing the aggregate patterns of adjustment that determine key outcomes at the economy-wide level.

\section{Conclusion}

Our review has shown that CGE-based studies conducted in the last two decades have attempted to capture various areas where health and non-health impacts of air pollution influence the behavior of agents in an economy. These modeling efforts are moving in the direction of increasing sophistication

in this dimension. However, there is no single study covers all the important channels outlined in our framework.

Future economy-wide benefit-cost assessments of air quality regulation should focus on four areas. First, current CGE models do not evaluate mortality risk in a way that is comparable to VSL-based methods or theoretically sound. We recommend a dynamic setting, in which households take the expected utility derived from lifetime consumption and amenities into account. Second, many air pollutants are localized and have different impacts on people with different backgrounds. Researchers should model this heterogeneity. Third, deeper study of the role of household migra- 
tion as a consequence of variation in local air quality is needed. We acknowledge the complexities of the task of addressing all of these different dimensions of the problem. However, it is worth testing each dimension, at least separately, to determine the the feasibility and necessity of incorporating these feature of the problem for a variety of research questions. Fourth, the lack of parameters of household preference prevents researchers from credibly identifying the changes in welfare or other economic indicators that caused by an environmental shock. We recommend empirical research on estimating demand systems which include both market and non-market goods at spatial/demographic units of analysis that are compatible with CGE models to improve environmental policy assessment. 


\section{References}

Ayres, R. U. and A. V. Kneese, "Production, Consumption and Externalities," American Economic Review, 1969, 59 (3), 282-297.

Bayer, Patrick, Nathaniel Keohane, and Christopher Timmins, "Migration and hedonic valuation: The case of air quality," Journal of Environmental Economics and Management, 2009, $58(1), 1-14$.

Bovenberg, A. L. and R. A. de Mooij, "Environmental Levies and Distortionary Taxation," American Economic Review, 1994, 84 (4), 1085-1089.

Carbone, J. C. and V. K. Smith, "Evaluating policy interventions with general equilibrium externalities," Journal of Public Economics, 2008, 92 (5), 1254 - 1274.

_ and _, "Valuing nature in a general equilibrium.," Journal of Environmental Economics and Management, 2013, 66 (1), 72-89.

Chang, Tom Y., Joshua Graff Zivin, Tal Gross, and Matthew Neidell, "The Effect of Pollution on Worker Productivity: Evidence from Call Center Workers in China," American Economic Journal: Applied Economics, 2019, 11 (1), 151-72.

Espinosa, J Andrés and V Kerry Smith, "Measuring the environmental consequences of trade policy: a nonmarket CGE analysis," American Journal of Agricultural Economics, 1995, 77 (3), $772-777$.

Giesecke, James A and John R Madden, "Migration Responses to a Loss in Regional Amenities: An Analysis with a Multiregional CGE Model," in "Socioeconomic Environmental Policies and Evaluations in Regional Science," Springer, 2017, pp. 249-277.

Gouveia, Nelson and Tony Fletcher, "Time series analysis of air pollution and mortality: effects by cause, age and socioeconomic status," Journal of Epidemiology $\& 5$ Community Health, $2000,54(10), 750-755$. 
Graff Zivin, J. and M. Neidell, "Environment, health, and human capital.," Journal of Economic Literature, 2013, 51 (3), 689-730.

Hanna, Rema and Paulina Oliva, "The effect of pollution on labor supply: Evidence from a natural experiment in Mexico City," Journal of Public Economics, 2015, 122, 68-79.

Hazilla, M. and R. J. Kopp, "Social Cost of Environmental Quality Regulations: A General Equilibrium Analysis," Journal of Political Economy, 1990, 98 (4), 853-873.

III, C Arden Pope and Douglas W Dockery, "Epidemiology of particle effects," in "Air pollution and health," Elsevier, 1999, pp. 673-705.

_, Richard T Burnett, Michael J Thun, Eugenia E Calle, Daniel Krewski, Kazuhiko Ito, and George D Thurston, "Lung cancer, cardiopulmonary mortality, and long-term exposure to fine particulate air pollution," Jama, 2002, 287 (9), 1132-1141.

Jones, Charles I. and Peter J. Klenow, "Beyond GDP? Welfare across countries and time," American Economic Review, 2016, 106 (9), 2426-2457.

Ko, Fanny WS, W Tam, Tze Wai Wong, CKW Lai, GWK Wong, T-F Leung, SSS Ng, and DSC Hui, "Effects of air pollution on asthma hospitalization rates in different age groups in Hong Kong," Clinical $\&$ Experimental Allergy, 2007, 37 (9), 1312-1319.

Kuminoff, Nicolai V., V. Kerry Smith, and Christopher Timmins, "The New Economics of Equilibrium Sorting and Policy Evaluation Using Housing Markets," Journal of Economic Literature, December 2013, 51 (4), 1007-62.

Li, J. C. I., "Including the feedback of local health improvement in assessing costs and benefits of GHG reduction.," Review of Urban \& Regional Development Studies, 2002, 14 (3), 282-304.

Mathiesen, Lars, "Computation of economic equilibria by a sequence of linear complementarity problems," in "Economic equilibrium: model formulation and solution," Springer, 1985, pp. 144162. 
Matus, K., K. M. Nam, N. E. Selin, L. N. Lamsal, J. M. Reilly, and S. Paltsev, "Health damages from air pollution in China.," Global environmental change, 2012, 22 (1), 55-66.

_, T. Yang, S. Paltsev, J. M. Reilly, and K. M. Nam, "Toward integrated assessment of environmental change: air pollution health effects in the USA," Climatic Change, 2008, 88 (1), $59-92$.

Mayeres, I. and D. Van Regemorter, "Modelling the health related benefits of environmental policies and their feedback effects: a CGE analysis for the EU countries with GEM-E3.," The Energy Journal, 2008, pp. 135-150.

Murphy, Kevin M. and Robert H. Topel, "The value of health and longevity," Journal of Political Economy, 2006, 114 (5), 871-904.

Nakosteen, R. A. and M. A. Zimmer, "Determinants of regional migration by manufacturing firms," Economic Inquiry, 1987, 25 (2), 351-362.

Nam, K. M., N. E. Selin, J. M. Reilly, and S. Paltsev, "Measuring welfare loss caused by air pollution in Europe: A CGE analysis.," Energy Policy, 2010, 38 (9), 5059-5071.

Saari, Rebecca K, Noelle E Selin, Sebastian Rausch, and Tammy M Thompson, "A self-consistent method to assess air quality co-benefits from US climate policies," Journal of the Air $\&$ Waste Management Association, 2015, 65 (1), 74-89.

Selin, Noelle E, Shiliang Wu, Kyung-Min Nam, John M Reilly, Sergey Paltsev, Ronald G Prinn, and Mort D Webster, "Global health and economic impacts of future ozone pollution," Environmental Research Letters, 2009, 4 (4), 044014.

Smith, V Kerry, "ReflectionsIn Search of Crosswalks between Macroeconomics and Environmental Economics," Review of Environmental Economics and Policy, 2012, 6 (2), 298-317.

- and Min Qiang Zhao, "Evaluating Economy-Wide Benefit Cost Analyses," Technical Report, National Bureau of Economic Research 2016. 
US EPA, "The Benefits and Costs of the Clean Air Act from 1990 to 2020: Final Report," Technical Report, United State Environmental Protection Agency, Office of Air and Radiation 2011.

_ , "SAB Advice on the Use of Economy-Wide Models in Evaluating the Social Costs, Benefits, and Economic Impacts of Air Regulations," Technical Report EPA-SAB-17-012, United States Environmental Protection Agency, Science Advisory Board 2017.

Vennemo, H., "A dynamic applied general equilibrium model with environmental feedbacks.," Economic Modelling, 1997, 14 (1), 99-154.

Vrontisi, Zoi, Jan Abrell, Frederik Neuwahl, Bert Saveyn, and Fabian Wagner, "Economic impacts of EU clean air policies assessed in a CGE framework," Environmental science $\mathcal{E}$ policy, 2016, 55, 54-64.

Williams III, R. C., "Health effects and optimal environmental taxes," Journal of Public Economics, 2003, 87 (2), 323-335.

Wing, Ian Sue, "Computable general equilibrium models for the analysis of economy-environment interactions," Research tools in natural resource and environmental economics, 2011, 255.

Yang, Trent, Kira Matus, Sergey Paltsev, and John Reilly, "Economic benefits of air pollution regulation in the USA: An integrated approach," MIT JPSPGC Report, 2005, 113, 26.

Zhang, Xu, Xunmin Ou, Xi Yang, Tianyu Qi, Kyung-Min Nam, Da Zhang, and Xiliang Zhang, "Socioeconomic burden of air pollution in China: Province-level analysis based on energy economic model," Energy Economics, 2017, 68, 478-489.

Zivin, J. Graff and M. Neidell, "The Impact of Pollution on Worker Productivity," American Economic Review, 2012, $102(7), 3652-73$. 
Table 1: Summary of Surveyed Papers.

\begin{tabular}{|c|c|c|c|c|c|c|c|c|c|c|}
\hline \multirow{2}{*}{ Papers } & \multicolumn{2}{|c|}{ Level of Aggregation } & \multicolumn{2}{|c|}{ Environmental Goods } & \multicolumn{2}{|c|}{ Health Effects } & \multicolumn{3}{|c|}{ Non-Health Benefits } & \multirow[b]{2}{*}{$\begin{array}{l}\text { Migra- } \\
\text { tion } \\
\text { (Section } \\
3.3 \text { ) }\end{array}$} \\
\hline & Regions & $\begin{array}{c}\text { Demographic of } \\
\text { Each Region }\end{array}$ & Type & $\begin{array}{c}\text { (Ex)ogeneous } \\
\text { or } \\
\text { (En)dogenous } \\
\text { Emission }\end{array}$ & $\begin{array}{c}\text { Health Status } \\
\text { and Monetary } \\
\text { Budget } \\
\text { Interactions } \\
\text { (Section 3.1.1) }\end{array}$ & \begin{tabular}{|c|} 
Time \\
Allocation \\
and Labor \\
Productivity \\
(Section3.1.2)
\end{tabular} & $\begin{array}{c}\text { Non-use } \\
\text { Values } \\
\text { (Section } \\
3.2 .1 \text { ) }\end{array}$ & $\begin{array}{c}\text { Use } \\
\text { Value } \\
\text { (Sction } \\
3.2 .2 \text { ) }\end{array}$ & \begin{tabular}{|c|} 
Capital \\
Productivity \\
and \\
Depreciation \\
(Section 3.2.3)
\end{tabular} & \\
\hline $\begin{array}{c}\text { Espinosa } \\
\text { \& Smith, } \\
1995\end{array}$ & $\begin{array}{c}\text { European } \\
\text { Community, US, } \\
\text { Japan, and the } \\
\text { ROW }\end{array}$ & $\begin{array}{c}\text { One } \\
\text { representative } \\
\text { household }\end{array}$ & $\begin{array}{c}\mathrm{SOx} \\
\mathrm{NOx}, \mathrm{PM}\end{array}$ & $\begin{array}{l}\text { En (emission } \\
\text { from } \\
\text { production) }\end{array}$ & Yes & & & & & \\
\hline $\begin{array}{c}\text { Vennemo, } \\
1997\end{array}$ & $\begin{array}{l}\text { A small open } \\
\text { economy of } \\
\text { Norway }\end{array}$ & $\begin{array}{c}\text { One } \\
\text { representative } \\
\text { household }\end{array}$ & $\begin{array}{c}\text { SO2, } \\
\text { NOx, } \\
\text { CO, PM, } \\
\text { noise, } \\
\text { traffic }\end{array}$ & $\begin{array}{l}\text { En (link to } \\
\text { material and } \\
\text { fuel uses) }\end{array}$ & Yes & Yes & Yes & & Yes & \\
\hline Li, 2002 & $\begin{array}{l}\text { An open } \\
\text { economy of } \\
\text { Thailand }\end{array}$ & $\begin{array}{c}\text { Three } \\
\text { households: } \\
\text { agricultural, } \\
\text { non-agricultural, } \\
\text { and government- } \\
\text { employed } \\
\end{array}$ & $\begin{array}{c}\text { PM10, } \\
\text { CO2 }\end{array}$ & $\begin{array}{l}\text { En (emission } \\
\text { from } \\
\text { production } \\
\text { and } \\
\text { consumption) }\end{array}$ & Yes & Yes & & & & \\
\hline $\begin{array}{l}\text { Yang, } \\
2005\end{array}$ & $\begin{array}{c}\text { EPPA-HE } \\
\text { model, US and } \\
15 \text { international } \\
\text { regions }\end{array}$ & $\begin{array}{c}\text { One } \\
\text { representative } \\
\text { household }\end{array}$ & $\begin{array}{c}\text { O3, NO2, } \\
\text { SO2, CO, } \\
\text { PM2.5 } \\
\text { PM10 }\end{array}$ & Ex & Yes & Yes & & & & \\
\hline $\begin{array}{l}\text { Carbone } \\
\text { \& Smith, } \\
2008\end{array}$ & $\begin{array}{c}\text { A closed } \\
\text { economy of the } \\
\text { US }\end{array}$ & $\begin{array}{c}\text { One } \\
\text { representative } \\
\text { household }\end{array}$ & PM & $\begin{array}{c}\text { En (PM } \\
\text { emission from } \\
\text { production) }\end{array}$ & Yes & Yes & & Yes & & \\
\hline $\begin{array}{l}\text { Mayeres } \\
\text { \& Rege- } \\
\text { morter, } \\
2008\end{array}$ & $\begin{array}{c}14 \text { European } \\
\text { countries and } \\
\text { the ROW }\end{array}$ & $\begin{array}{l}\text { One } \\
\text { representative } \\
\text { household }\end{array}$ & $\begin{array}{c}\text { NOx, } \\
\text { SO2, } \\
\text { VOC, } \\
\text { PM, } \\
\text { CO2, } \\
\text { Traffic }\end{array}$ & \begin{tabular}{|c|} 
En (Bi- \\
directional \\
coupling of \\
the economy \\
and the \\
environment)
\end{tabular} & Yes & Yes & Yes & & & \\
\hline $\begin{array}{l}\text { Matus et. } \\
\text { al., } 2008\end{array}$ & $\begin{array}{c}\text { EPPA-HE } \\
\text { model, US and } \\
15 \text { international } \\
\text { regions }\end{array}$ & $\begin{array}{c}\text { One } \\
\text { representative } \\
\text { household }\end{array}$ & $\begin{array}{c}\text { O3, NO2, } \\
\text { SO2, CO, } \\
\text { PM2.5, } \\
\text { PM10 }\end{array}$ & Ex & Yes & Yes & & & & \\
\hline
\end{tabular}




\begin{tabular}{|c|c|c|c|c|c|c|c|c|c|c|}
\hline $\begin{array}{l}\text { Selin et. } \\
\text { al., } 2009\end{array}$ & $\begin{array}{l}\text { EPPA-HE } \\
\text { model, } 16 \\
\text { regions of the } \\
\text { global economy }\end{array}$ & $\begin{array}{c}\text { One } \\
\text { representative } \\
\text { household }\end{array}$ & O3 & Ex & Yes & Yes & & & & \\
\hline $\begin{array}{l}\text { Nam et. } \\
\text { al., } 2010\end{array}$ & $\begin{array}{c}\text { EPPA-HE } \\
\text { model, EU15+ } \\
(18 \text { countires }) \text { as } \\
\text { one region and } \\
15 \text { international } \\
\text { regions }\end{array}$ & $\begin{array}{c}\text { One } \\
\text { representative } \\
\text { household }\end{array}$ & $\begin{array}{c}\text { O3, } \\
\text { PM10 }\end{array}$ & Ex & Yes & Yes & & & & \\
\hline $\begin{array}{l}\text { US EPA, } \\
2011\end{array}$ & $\begin{array}{c}\text { Five regions in } \\
\text { the US }\end{array}$ & $\begin{array}{l}\text { Four income } \\
\text { groups of } \\
\text { working age } \\
\text { households } \\
\end{array}$ & PM, O3 & Ex & Yes & Yes & & & & \\
\hline $\begin{array}{l}\text { Matus et. } \\
\text { al., } 2012\end{array}$ & $\begin{array}{c}\text { EPPA-HE } \\
\text { model, China } \\
\text { and } 15 \\
\text { international } \\
\text { regions }\end{array}$ & $\begin{array}{c}\text { One } \\
\text { representative } \\
\text { household }\end{array}$ & $\begin{array}{l}\text { O3, } \\
\text { PM10 }\end{array}$ & Ex & Yes & Yes & & & & \\
\hline $\begin{array}{l}\text { Carbone } \\
\& \text { Smith, } \\
2013\end{array}$ & $\begin{array}{c}\text { A closed } \\
\text { economy of the } \\
\text { US }\end{array}$ & $\begin{array}{c}\text { One } \\
\text { representative } \\
\text { household }\end{array}$ & $\begin{array}{l}\mathrm{SO} 2 \\
\mathrm{NOx}\end{array}$ & $\begin{array}{l}\text { En (emission } \\
\text { from "full } \\
\text { consump- } \\
\text { tion") }\end{array}$ & & Yes & Yes & Yes & & \\
\hline $\begin{array}{l}\text { Saari et. } \\
\text { al., } 2015\end{array}$ & $\begin{array}{c}12 \text { regions in the } \\
\text { US }\end{array}$ & $\begin{array}{l}\text { Nine household } \\
\text { income groups }\end{array}$ & $\mathrm{PM}$ & $\mathrm{Ex}$ & Yes & Yes & & & & \\
\hline $\begin{array}{l}\text { Vrontisi } \\
\text { et. al., } \\
2016\end{array}$ & $\begin{array}{l}\text { EU-28 as on } \\
\text { region and } 10 \\
\text { international } \\
\text { regions }\end{array}$ & $\begin{array}{c}\text { One } \\
\text { representative } \\
\text { household }\end{array}$ & $\begin{array}{l}\text { PM2.5, } \\
\text { SO2, } \\
\text { NOx, } \\
\text { VOCs, } \\
\text { NH3 }\end{array}$ & Ex & Yes & Yes & & & Yes & \\
\hline $\begin{array}{l}\text { Smith \& } \\
\text { Zhao, } \\
2016\end{array}$ & $\begin{array}{c}\text { A closed } \\
\text { economy of the } \\
\text { US }\end{array}$ & $\begin{array}{c}\text { One } \\
\text { representative } \\
\text { household }\end{array}$ & PM & $\begin{array}{l}\text { En (emission } \\
\text { from market } \\
\text { goods) }\end{array}$ & Yes & Yes & & & & \\
\hline $\begin{array}{l}\text { Zhang et. } \\
\text { al., } 2017\end{array}$ & \begin{tabular}{|c}
30 Chinese \\
provinces and 5 \\
international \\
regions \\
\end{tabular} & $\begin{array}{l}\text { One } \\
\text { representative } \\
\text { household }\end{array}$ & PM2.5 & Ex & Yes & Yes & & & & \\
\hline $\begin{array}{c}\text { Giesecke } \\
\& \\
\text { Madden, } \\
2017 \\
\end{array}$ & $\begin{array}{c}\text { Three regions in } \\
\text { Australis and } \\
\text { the ROW }\end{array}$ & $\begin{array}{c}\text { One } \\
\text { representative } \\
\text { household }\end{array}$ & $\begin{array}{c}\text { Regional } \\
\text { amenities }\end{array}$ & Ex & & & & & & Yes \\
\hline
\end{tabular}

